\title{
Quid novi in the eldery patient's anesthesia
}

\author{
B Lettieri, ML Mingione, A d'Elia, P Capodanno \\ From XXIII Annual Meeting of the Italian Society of Geriatric Surgery \\ Lecce, Italy. 2-4 December 2010
}

\section{Background}

Today the availability of new local anesthetics and the use of analgesics, allow the modulation of the analgesia, maintaining a state of consciousness.

An answer to the needs of patients $>75$ years undergoing surgery is the technique Monitored Anesthesia Care (MAC), defined "the middle land" (Figure 1).

MAC allows:

- the modulation of the level of analgesia at different stages of surgery due to the availability of analgesic action, but with rapid onset-time

- the additional analgesia using local anesthetics with prolonged effect without the use of noradrenaline, dangerous for elderly patients

the consciousness and cooperation of the patient (Table 1).

\section{Materials and methods}

With this study we tested the efficacy, safety and limitations of the MAC.

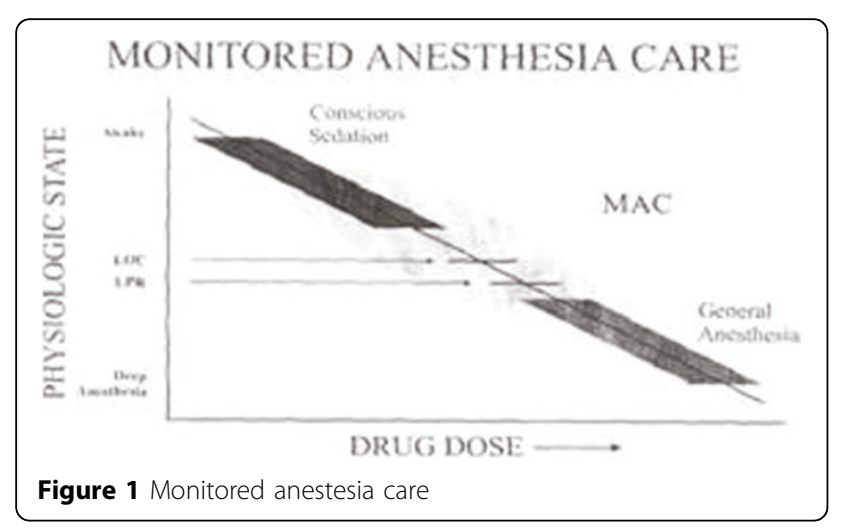

* Correspondence: biagio.lettieri@unina2.it
Department of Anaesthesia, Surgical and Emergency Science, Second
University of Naples, Italy
Table 1 MAC.

\begin{tabular}{ll}
\hline Conscious Sedation(MAC) & Unconscious Sedation \\
\hline Altered consciousness & Unconsciousness \\
Conscious patient & Unconscious patient \\
Protective reflexes intact and active & Protective reflexes decreased; \\
& airway obstruction may occur \\
& Ventilation: hypoxia, hypercapnia \\
& Cardiovascular system: , \\
& hypotension, hypertension, \\
& bradycardia, tachycardia \\
Stable vital signs & Unstable vital signs \\
Analgesia may be present; need for & Pain controlled centrally; does \\
regional analgesia / local or systemic & not require regional analgesia \\
Limited stay in the units of & Requiring hospitalization or \\
observation & prolonged hospitalization \\
Low risk of complications & High risk of complications \\
Infrequent postoperative & Frequent postoperative \\
complications & complications \\
Patients with psychiatric problems or & May be needed to manage \\
mental deficiency may be difficult to & patients with mental deficiency \\
manage &
\end{tabular}

The design of the study was a prospective, doubleblind, parallel-group, with 42 patients randomly selected from 87 patients recruited between those eligible for inclusion in the circuit one-day surgery (Table 2)

Two groups were subjected to two different regimes of sedation with propofol and midazolam, pain controlled with remifentanil.

- Primary end-point was verifying the level and quality of sedation achieved

- Secondary end-point was identifying and quantifying potential adverse effects (Table 3-4)

Table 2 Patients' criteria of homogeneity.

\begin{tabular}{l} 
Patients' criteria of homogeneity \\
\hline same level of gravity ASA II/III \\
NYHA II class \\
same duration of surgery (40 min $\pm 10 \mathrm{~min}$ \\
\hline
\end{tabular}


Table 3 Access Criteria.

\section{ACCESS CRITERIA}

Weight $69 \pm 6 \mathrm{Kg}$

Informed consent for MAC procedures

ASA II/II with stabilized cardio-circulatory impairments and respiratory parameters: $\mathrm{pO}_{2} \leq 70$ e $\mathrm{pCO}_{2}<45 \mathrm{mmHg}$

Patients undergoing operations can be managed only with the cooperation of the patient

Age $>75$ years

Table 4 Exclusion Criteria.

\section{EXCLUSION CRITERIA}

Patient desire

ASA III impairment of vital organs in acute and evolutionary phase

Patients with unexpected rapid intubation

Patients with high risk of bleeding

Severe neurological disorders

Levels of sedation, pain and mental status were assessed using different clinical approaches :

- Observational data (Table 5).

We proceeded as follows:

1) $\mathrm{O}_{2}$ inhalation $\left(\mathrm{SpO}_{2}>98\right.$ and normocapnia)

2) during surgical manipulation a continuous infusion of remifentanil: 0.03 to $0.06 \mathrm{mg} / \mathrm{kg} / \mathrm{h}$ was activated

Patients were randomly dichotomized into two arms with two different infusion regimens:

-group P (45 patients): starter bolus of $0.5 \mathrm{mg} / \mathrm{kg}$ propofol (to fill the central compartment) $\rightarrow \mathrm{P}$ infusion of 1-2 $\mathrm{mg} / \mathrm{kg} / \mathrm{h}$ (to offset the rapid deployment)

-group M (41 patients): bolus starter from 0.03 to 0.05 $\mathrm{mg} / \mathrm{kg}$ midazolam (average dose of 2-4 mg) infusion of $1-2 \mathrm{mg} / \mathrm{kg} / \mathrm{h}$

Every 10 m' scores are recorded, BIS and OAA / S scale.

- objective parameters based on Ramsay Scale (Table 6).

- Instrumental response with Bispectral Index (Table 789)

Table 5 Observer' s assessment of alertness/sedation scale (oaa/s scale).

\begin{tabular}{|c|c|c|c|c|}
\hline Answer & Verbal expression & Facial expression & Eyes & \\
\hline Ready to the call, normal tone & Normal & Normal & Normal & 5 \\
\hline Torpid to the call, normal tone & Initial slowdown & Medium relaxation & Medium relaxation & 4 \\
\hline Only for repeat calls with high tone & slowdown & Marked relaxation & Marked ptosis & 3 \\
\hline Only if shaken & Not understandable words & - & - & 2 \\
\hline No answers, even if shaken & - & - & - & 1 \\
\hline
\end{tabular}

Table 6 Ramsay Scale.

\begin{tabular}{ll}
\hline 1 & Patient anxious and agitated or restless, or both \\
\hline 2 & Patient co-operative, orientated and tranquil \\
4 & Patient responds to commands only \\
5 & Brisk response to a light glabellar tap or auditory stimulus \\
6 & Sluggish response to a light glabellar tap or auditory stimulus \\
\hline
\end{tabular}

Table 7 Average values of clinical and instrumental group $\mathbf{P}$.

\begin{tabular}{lllll}
\hline & T10m & T20m & T30m & T40m \\
\hline BIS & $72(42-45)$ & $66(35-88)$ & $70(55-82)$ & $74(52-88)$ \\
OAA/S & $4(1-5)$ & $3-4(1-5)$ & $3-4(1-5)$ & $4(1-5)$ \\
\hline
\end{tabular}

Table 8 Average values of clinical and instrumental group M.

\begin{tabular}{cllll}
\hline & T10m & T20m & T30m & T40m \\
\hline BIS & $64(48-86)$ & $58(35-73)$ & $62(36-84)$ & $66(48-83)$ \\
OAA/S & $4(1-5)$ & $3-4(1-5)$ & $3-4(1-5)$ & $4(1-5)$ \\
\hline
\end{tabular}


Table 9 Propofol, Midazolam, Remifentanil during MAC.

\begin{tabular}{llll}
\hline & Propofol & Midazolam & Remifentanil \\
\hline $\begin{array}{l}\text { onset of sedation } \\
\text { resolution pharmacological effects }\end{array}$ & rapid & moderate & rapid \\
injection pain & rapid & lenta & rapid \\
intraoperative and postoperative pain & yes & no & no \\
hemodynamic depression & moderate & moderate & minimum \\
respiratory variations & moderate & minimum & minimum \\
PONV & mild desaturation $(<30 \%)$ & minimum & moderate \\
\hline
\end{tabular}

\section{Conclusions}

The combination midazolam-remifentanil presented a lower synergistic effect compared with propofol-remifentanil. The first fact documented a mean BIS of 62.5 +3 vs. $64.7+4$ midazolam-remifentanil association and has finally, although sporadic, incidents of desaturation content and never $>30 \%$. The evaluation of the kinetic values of $\mathrm{BIS}$, the interesting fact that emerges concerns the values $>70$, which represented a significant predictor in the study to better recovery of consciousness, which has helped the fast-traking ongoing day-surgery.

Published: 24 August 2011

\section{References}

1. Kenny DN: Patient sedation: technical problems and developements. Eur J Anesth 1996, 13:18-21, discussion 22-5.

2. Liu J, Singh $H$, White PF: EEG: BIS correlates with intraoperative recall and depth of propofol induced sedation. Anesth Analg 1997, 84(1):185-9.

3. Dexter F, Aker J, Wright WA: Development of a measure of patient satisfaction with monitored anesthesia care:the Jawa Satisfaction with Anesthesia Scale. Anesthesiology 1997, 87(4):865-73.

4. Murdoch JA, Hyde RA, Kenny GN: Target-controlled remifentanyl in combination with propofol for spontaneously breathing day-care patients. Anaesth 1999, 54(11):1028-31.

5. Rego JA, White MM: What is new in monitored anesthesia care? Anesth 1998, 11:601-6.

6. Corck RC, Guillory EA: Effect of patient -controlled sedation on recovery from ambulatory monitored anesthesia care. An J Anesth 1995, 22(2):94-100.

7. Twersy SR: The ambulatory anesthesia handbook. St. Louis, Ed.Mosby 1997.

\section{doi:10.1186/1471-2318-11-S1-A26}

Cite this article as: Lettieri et al:: Quid novi in the eldery patient's anesthesia. BMC Geriatrics 2011 11(Suppl 1):A26.

\section{Submit your next manuscript to BioMed Central} and take full advantage of:

- Convenient online submission

- Thorough peer review

- No space constraints or color figure charges

- Immediate publication on acceptance

- Inclusion in PubMed, CAS, Scopus and Google Scholar

- Research which is freely available for redistribution

Submit your manuscript at www.biomedcentral.com/submit
C Biomed Central 